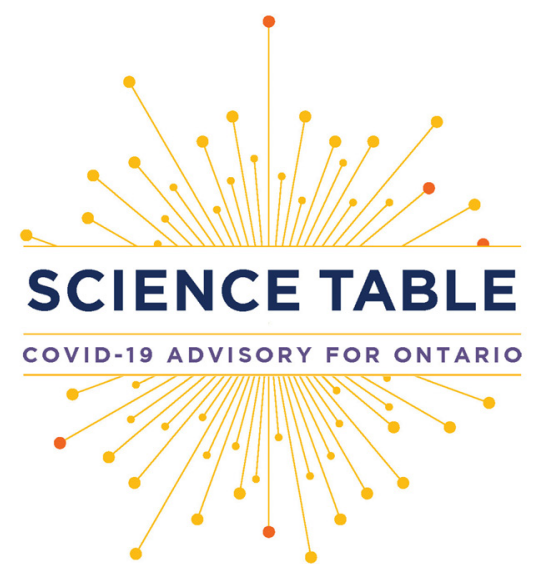

Version: $\mathbf{1 . 0}$

Published: November 30, 2021

Citation: Barrett KA, VandeVyvere C, Haque $\mathrm{N}$, et al. Critical care capacity during the COVID-19 pandemic. Science Briefs of the Ontario COVID-19 Science Advisory Table. 2021;2(51). https://doi.org/10.47326/ ocsat.2021.02.51.1.0

Author Affiliations: The affiliations of the members of the Ontario COVID-19 Science Advisory Table can be found at https:// covid19-sciencetable.ca/.

Declarations of Interest: The declarations of interest of the members of the Ontario COVID-19 Science Advisory Table, its Working Groups, or its partners can be found at https:// covid19-sciencetable.ca/. The declarations of interest of external authors can be found under additional resources at https://doi. org/10.47326/ocsat.2021.02.51.1.0

About Us: The Ontario COVID-19 Science Advisory Table is a group of scientific experts and health system leaders who evaluate and report on emerging evidence relevant to the COVID-19 pandemic, to inform Ontario's response. Our mandate is to provide weekly summaries of relevant scientific evidence for the COVID-19 Health Coordination Table of the Province of Ontario, integrating information from existing scientific tables, Ontario's universities and agencies, and the best global evidence. The Science Table summarizes its findings for the Health Coordination Table and the public in Science Briefs.

Correspondence to: Secretariat of the Ontario COVID-19 Science Advisory Table (info@covid19-sciencetable.ca)

Copyright: 2021 Ontario COVID-19 Science Advisory Table. This is an open access document distributed under the terms of the Creative Commons Attribution License, which permits unrestricted use, distribution, and reproduction in any medium, provided that the original work is properly cited.

The views and findings expressed in this Science Brief are those of the authors and do not necessarily reflect the views of all of the members of the Ontario COVID-19 Science Advisory Table, its Working Groups, and its partners.
SCIENCE BRIEFS

\section{Critical Care Capacity During the COVID-19 Pandemic}

Kali A. Barrett, Cindy VandeVyvere, Nasim Haque, Meiyin Gao, Shujun Yan, Gerald Lebovic, Ian Ball, Nicolas S. Bodmer, Karen B. Born, Sonny Dhanani, Niall D. Ferguson, David Neilipovitz, Anna Perkhun, Michael Scott, Michael Sullivan, Josée Thériault, Laveena Munshi, Arthur S. Slutsky, Peter Jüni, Andrew J. Baker, on behalf of the Ontario COVID-19 Science Advisory Table

\section{Key Message}

From March 20, 2020 to October 31, 2021, 9,096 Ontarians have been admitted to intensive care units (ICUs) with COVID-19 related critical illness. The COVID-19 pandemic has strained Ontario's critical care system. At the peak of wave 3, the number of patients on ventilators was over $180 \%$ of pre-pandemic historical averages.

The critical care system was able to accommodate this influx of patients by deferring surgeries and procedures, funding new ICU beds, identifying temporary surge space, team-based care models utilizing redeployed staff, and transferring patients between hospitals. This required effective collaboration and coordination across critical care system.

The critical care system does not currently have capacity to accommodate a surge as it did during waves 2 and 3 due to worsening staffing shortages, healthcare worker burnout, and health system recovery efforts. Public health measures to mitigate influxes of critically ill patients are needed.

\section{Summary}

Large numbers of patients with COVID-19 related critical illness (CRCI) requiring ICU care has placed considerable strain on Ontario's critical care system. This brief outlines how the Ontario critical care system has accommodated the surge of COVID-19 patients to date, focusing on critical capacity as it relates to physical space and healthcare workers.

\section{Questions}

How is Ontario's critical care system structured?

How has the COVID-19 pandemic affected Ontario's ICUs?

How has the Ontario critical care system adapted to meet the increased demand for critical care resources?

What is the current status of the Ontario critical care system, and what are the potential threats over the coming months?

\section{Findings}

There has been significant and unprecedented situational awareness, collaboration, and coordination between Ontario's critical care stakeholders and partners in the COVID-19 pandemic. Active data monitoring, sharing, and reporting was crucial.

ICU resources and staffing were not sufficient during COVID-19 surges. In May 2021, at the peak of wave 3 the number of adult patients requiring invasive mechanical 
ventilation (IMV) in Ontario ICUs was $180 \%$ of the pre-pandemic historic average.

Several strategies were employed to expand ICU capacity including using ward beds to care for non-ventilated $\mathrm{CRCl}$ patients on high fractions of inspired oxygen and identifying non-traditional spaces for ICU surge capacity. Nurse to patient ratios were increased and redeployed nurses worked in team-based models of care overseen by a critical care nurse.

Patients presenting to hospital with $\mathrm{CRCl}$ requiring ICU admission have clustered in regions with the highest burden of SARS-CoV-2 transmission. Between January 5, 2021, and July 4, 2021, 976 critically ill patients were transferred between and within regions. These transfers, in addition to proactive transfers of acute care patients, avoided overwhelming hospitals in these regions.

Health system recovery is now a key priority, with Ontario Health recommending that hospital operations over the coming months preserve access to non-COVID-19 scheduled surgeries, procedures, and diagnostic imaging.

Recent modelling suggests that there may be an increased number of patients with $\mathrm{CRCl}$ alongside influenza over the 2021/2022 winter months, driving an increase in potential ICU admissions. There is a growing ICU staffing shortage with increases in nurse vacancy rates in particular across the provinces' ICUs. Burnout, which has been exacerbated by the COVID-19 pandemic and in particular impacts nurses, is a significant contributor to staffing shortages.

\section{Interpretation}

It may be more challenging for the critical care system to rapidly increase capacity as it did during prior pandemic waves. Public health measures are needed in the short term to reduce transmission of SARS-CoV-2 as well as other infectious diseases, including influenza. Longer-term policies need to be simultaneously implemented to address the existing critical care staffing crisis. These combined efforts will help ensure that there is critical care capacity for all patients who require it, and reduce the burden on an already strained workforce.

\section{Background}

The COVID-19 pandemic has placed considerable strain on Ontario's healthcare system. Large numbers of individuals have required admission to ICUs with $\mathrm{CRCl}$. Because of significant investments in new resources and highly effective coordination and collaboration within the health system, the unprecedented number of patients who have needed critical care received it. These coordinated efforts meant that the province was able to avoid the worst-case scenario in which the number of patients needing critical care would exceed the system's resources, potentially triggering the use of a triage framework to ration critical care resources.

While these efforts have largely been successful in ensuring that clinical resources are available for patients with COVID-19, they are also associated with delay or deferral of non-COVID-related clinical activity and placed a considerable burden on the health system workforce.

This brief outlines how the Ontario critical care system has met the challenge of the COVID-19 pandemic thus far, focusing on critical care capacity as it relates to physical space and critical care healthcare professionals. It does not address other consumables and resources that have also, at times, been in short supply, including medication, personal protective equipment, and high-flow nasal cannula.

\section{Questions}

How is Ontario's critical care system structured? 
How has the COVID-19 pandemic affected Ontario's ICUs?

How has the Ontario critical care system adapted to meet the increased demand for critical care resources?

What is the current status of the Ontario critical care system, and what are the potential threats over the coming months?

\section{Findings}

\section{How Is Ontario's Critical Care System Structured?}

Prior to the COVID-19 pandemic there were 2,012 adult intensive care beds in the 184 ICUs in Ontario's critical care system. Approximately 65\% of the ICU beds in Ontario are presently staffed and resourced to provide care to the most acutely ill patients who require IMV. Some of the remaining beds have the capacity to provide cardiovascular support using vasoactive/inotropic medications, and all can provide closer supervision and monitoring than would be available in a medical or surgical ward bed. The level of support available in any given ICU in Ontario is described by the ICU level: level 2 ICUs are able to provide close observation and some organ support, while the level 3 ICUs can provide IMV and other more complex organ support (see Table 1). Some of the ICUs are designated for specific patient populations, e.g.: ICUs for burn patients, cardiac ICUs for patients with cardiac disease, and cardiovascular ICUs for patients recovering from cardiovascular surgery. ICUs in Ontario are distributed over a large geographic area and they vary in size ranging from one bed to more than 50 .

\begin{tabular}{|c|c|c|c|}
\hline $\begin{array}{l}\text { Level of } \\
\text { Intensive } \\
\text { Care Unit }\end{array}$ & Ability to Provide Ventilation & $\begin{array}{l}\text { Ability to Provide Vasoactive/ } \\
\text { Inotropic Medications/Arterial } \\
\text { Line Monitoring }\end{array}$ & $\begin{array}{c}\text { Typical Staffing/ } \\
\text { Occupancy }\end{array}$ \\
\hline $\begin{array}{l}\text { Level } 2 \\
\text { Basic }\end{array}$ & $\begin{array}{l}\text { - } \\
\text { - Capable of short-term } \\
\text { (<48h) support of IMV for } \\
\text { non-chronic long-term } \\
\text { IMV patients } \\
\text { - Capable of supporting } \\
\text { stable chronic long-term } \\
\text { IMV patients } \\
\text { - } 1 \% \text { of patient days with } \\
\text { IMV }\end{array}$ & - None & $\begin{array}{l}\text { May be multiple } \\
\text { physicians designat- } \\
\text { ed MRP } \\
\text { - } 1 \text { nurse: } 2 \text { patients } \\
\text { usual staffing ratio }{ }^{\text {a }} \\
\text { - Average annual } \\
\text { occupancy } 40 \% \text { or } \\
\text { more }\end{array}$ \\
\hline $\begin{array}{l}\text { Level } 2 \\
\text { Advanced }\end{array}$ & $\begin{array}{l}\text { - NIV capable } \\
\text { Capable of providing } \\
\text { invasive mechanical ven- } \\
\text { tilation for short period, } \\
\text { or IMV for chronic IMV/ } \\
\text { weaning } \\
\text { - }<10 \% \text { of patient days with } \\
\text { IMV }\end{array}$ & $\begin{array}{l}\text { - Some patient days with } \\
\text { vasoactive/inotropic med- } \\
\text { ication }\end{array}$ & $\begin{array}{l}\text { Single physician as } \\
\text { MRP (intensivist or } \\
\text { other) } \\
\text { - } 1 \text { nurse: } 2 \text { patients } \\
\text { usual staffing ratio } \\
\text { - Average annual } \\
\text { occupancy } 50 \% \text { or } \\
\text { more }\end{array}$ \\
\hline $\begin{array}{l}\text { Level } 3 \\
\text { Basic }\end{array}$ & $\begin{array}{l}\text { - NIV capable } \\
\text { IMV capable (at least } 35 \% \\
\text { of beds) } \\
\text { - At least } 10 \% \text { of patient } \\
\text { bed days with IMV }\end{array}$ & $\begin{array}{l}\text { At least } 5 \% \text { of patient bed } \\
\text { days with single or multiple } \\
\text { vasoactive/inotropic infu- } \\
\text { sions } \\
\text { - At least } 10 \% \text { of patient } \\
\text { bed days with arterial line } \\
\text { monitoring }\end{array}$ & $\begin{array}{l}\text { Must have } 24 / 7 \\
\text { respiratory therapy } \\
\text { support } \\
\text { - Intensivist as MRP } \\
\text { recommended } \\
\text { - Average annual } \\
\text { occupancy } 60 \% \text { of } \\
\text { more } \\
1 \text { nurse: } 1 \text { vented }^{\text {patient }^{\mathrm{a}}}\end{array}$ \\
\hline
\end{tabular}




\begin{tabular}{|c|c|c|c|}
\hline & & & $\begin{array}{l}\text { - } 1 \text { nurse: } 2 \text { patients } \\
\text { if not vented or low } \\
\text { acuity }^{\text {a }}\end{array}$ \\
\hline $\begin{array}{l}\text { Level } 3 \\
\text { Advanced }\end{array}$ & $\begin{array}{l}\text { - NIV capable } \\
\text { - IMV capable (at least } 50 \% \\
\text { of beds) } \\
\text { - At least } 30 \% \text { of patient } \\
\text { bed days with IMV }\end{array}$ & $\begin{array}{l}\text { - At least } 1 \% \text { of bed days } \\
\text { with multiple vasoactive/ } \\
\text { inotropic infusions } \\
\text { - At least } 15 \% \text { of patient } \\
\text { bed days with arterial line } \\
\text { monitoring }\end{array}$ & 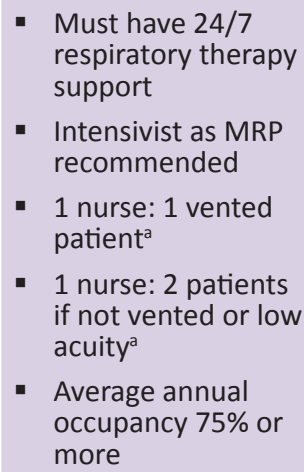 \\
\hline $\begin{array}{l}\text { Level } 2 \\
\& 3 \\
\text { Coronary }\end{array}$ & TBD & TBD & TBD \\
\hline
\end{tabular}

Table 1. Description of the Different Levels of Ontario Intensive Care Units (ICUs)

Adapted from Adult Critical Care Levels of Care. Guidance Document. Critical Care Services Ontario. November 2020. Available at: https://criticalcareontario.ca/wp-content/uploads/2020/11/Adult-LoC-Guidance-Document-Final.pdf.

${ }^{a}$ Nursing ratios not reported in CCSO Guidance Document.

${ }^{b}$ Descriptions of coronary units under development as per 2020 CCSO report.

CCSO, Critical Care Services Ontario. IMV, invasive mechanical ventilation. NIV, non-invasive ventilation. MRP, most responsible physician.

ICUs are staffed by large interprofessional teams of healthcare professionals. The teams typically include at least one physician trained in critical care medicine (also called an intensivist), consulting physicians, nurses with specialized training and certification in critical care nursing, respiratory therapists, pharmacists, physiotherapists, occupational therapists, speech language pathologists, social workers, and spiritual counsellors or chaplains. Given the complexity and acuity of critically ill patients in level 3 ICUs, nurses are typically only responsible for one patient during a shift. Nurses can be assigned to more than one patient if the patients do not require IMV or are on minimal or no organ support. In large ICUs, the care of patients is often split between multiple intensivists so that one physician is only responsible for approximately 12 15 patients. Indeed, data suggests that patient outcomes are better when a single intensivist is responsible for fewer than 14 patients at once. ${ }^{1}$ The clinical complexity of these patients and the resources required to care for them are reflected in the costs: according to the Canadian Institute for Health Information (CIHI), one day in the ICU costs approximately three times more than one day in a ward bed (average daily cost in ICU $\$ 3,592$ versus $\$ 1,135$ in general ward), with the highest costs occurring in large academic teaching hospitals $(\$ 4,186$ per day in ICU versus $\$ 1,492$ per day in ward; all amounts in 2014 CAD). ${ }^{2}$

\section{How Has the COVID-19 Pandemic Affected Ontario's ICUs?}

\section{Number of Patients Admitted with COVID-19-Related Critical Illness (All Ages)}

Between March 20, 2020, and October 31, 2021, the cumulative number of patients admitted to an Ontario ICU with CRCI was $9,096(9,020>18$ years old, and $76<18$ years old). Individuals with severe COVID-19 requiring admission to ICU have presented in waves corresponding to the pattern of community transmission (see Figure 1). 


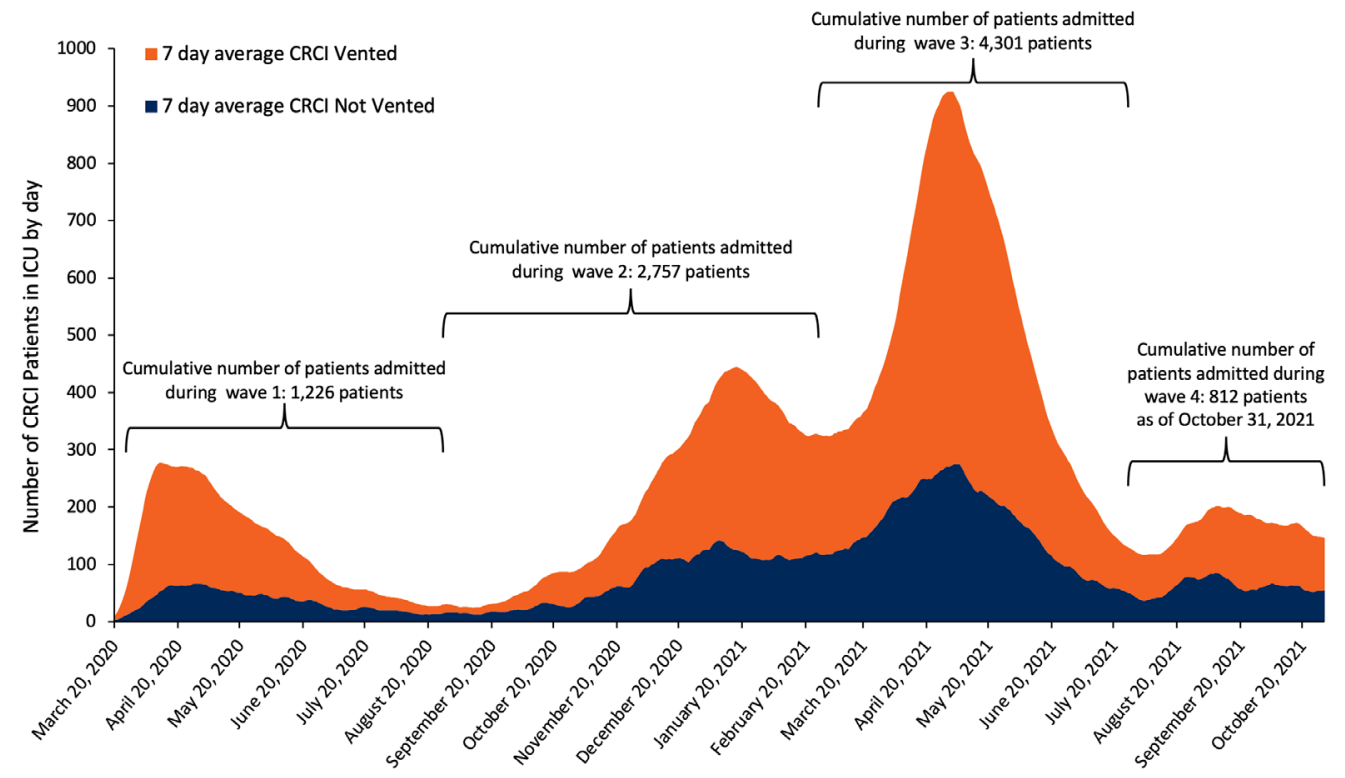

Figure 1. Daily Census of Patients (All Ages) With CRCI in Ontario ICUs Vented and Non-vented CCSO and the Ministry of Health define wave 1 from March 2020 to August 31, 2020; wave 2 from September 1, 2020 to February 28, 2021; wave 3 from March 1, 2021 to July 31, 2021; and wave 4 as of August 1, 2021. CCSO, Critical Care Services Ontario. CRCI, COVID-19 related critical illness. ICU, intensive care unit.

The peak number of patients in ICUs with CRCI during wave 1 was on April 12, 2020 (283 patients), the peak in wave 2 was on January 15, 2021 (450 patients with $\mathrm{CRCl}$ in ICU), and the peak of wave 3 was on April 30, 2021 (940 patients with $\mathrm{CRCl}$ in ICU). ${ }^{3}$ Wave 4 has, as of October 31,2021, been characterized by a stable number of new admissions and a less pronounced peak.

\section{Patient Outcomes}

According to the CCSO Weekly Summary reporting up to October 31, 2021, of the 9,096 cumulative individuals (all ages) admitted to an ICU with $\mathrm{CRCl}, 5,969$ (65.6\%) have been discharged alive from ICU. 2,985 (32.8\%) have died in ICU, which is comparable to the mortality rate observed in other jurisdictions. ${ }^{4}$ As of October 31 , $142(1.6 \%)$ of the 9,096 cumulative patients admitted with CRCI were still in an ICU. Among all patients admitted to ICU with $\mathrm{CRCl}, 63.2 \%$ have required IMV, $14.7 \%$ have received renal replacement therapy (dialysis), and 3.6\% have received extracorporeal membrane oxygenation (ECMO). The duration of organ support has been long: $17.9 \%$ of patients admitted to ICU with $\mathrm{CRCI}$ have required IMV for more than 30 days.

\section{Effect of COVID-19 Pandemic on Provincial Adult ICU Censuses}

The following analyses explore how the number of adult patients in Ontario ICUs changed during the pandemic period compared to the pre-pandemic period. As a result of the increased number of patients needing critical care beds during the pandemic, some hospitals changed their protocols regarding which types of patients were admitted to specific ICUs, e.g., admitting $\mathrm{CRCl}$ patients to cardiac surgical ICUs. These changes happened fluidly and are not easily tracked in the Critical Care Information System (CCIS) database. Therefore, to fully capture the impact of the pandemic on the critical care system, we chose to analyze the impact of COVID-19 by considering all adult critical care beds in our analysis.

We have stratified our analysis of the daily census during the pandemic period to those patients receiving IMV, also called vented, and patients not receiving IMV (notvented). We used the CCIS total census for the reported day, which was provided courtesy of Critical Care Services Ontario (CCSO). ${ }^{3}$ The census numbers may be slightly different than those in the CCSO Daily Reports, which report the census in CCIS as of 23:59 on the reported day. 
We calculated the pre-pandemic historical average census for each day of the year using census data from January 1, 2016, to December 31, 2019. We calculated the historical daily average census to account for the temporal or seasonal changes in the number of patients in ICUs. These historical average daily ICU censuses were determined for: 1 ) the total number of patients; 2 ) the number of vented patients; and 3) the number of non-vented patients. CCSO began identifying patients with $\mathrm{CRCl}$ in the CCIS database on March 20, 2020, and therefore we consider this date to be the start of the pandemic period; however, the WHO declared the COVID-19 pandemic on March 11, 2020.

When compared to the historical average total daily census, wave 1 was associated with a lower-than-average number of patients in ICUs. Wave 2 and wave 3 were associated with daily ICU censuses well above historical averages. Thus far, wave 4 has not been associated with the same rapid increase in the number of patients with $\mathrm{CRCI}$ needing critical care.

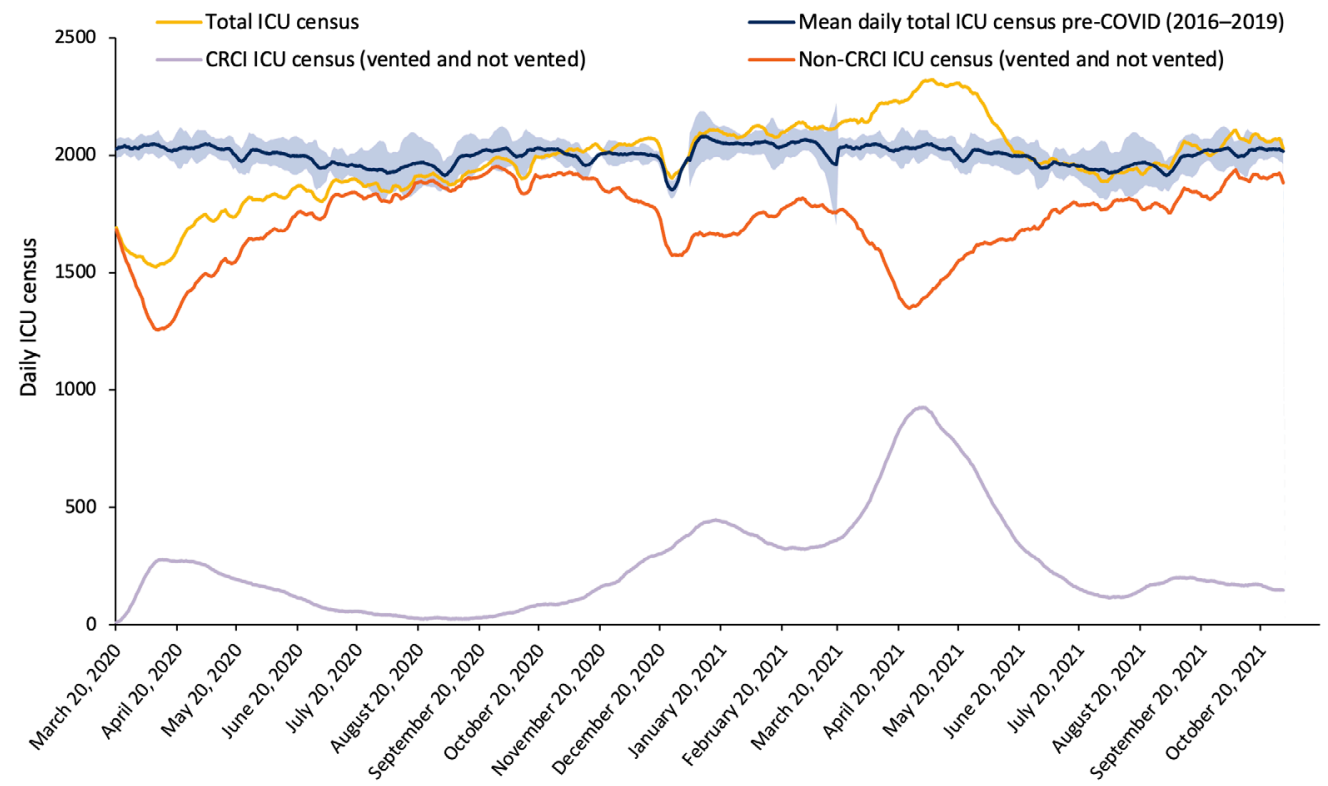

Figure 2. Total Adult ICU Census, CRCI, and Non-CRCl Censuses during Pandemic Period, Compared to Mean Daily Total ICU Census for Pre-pandemic Period (2016-2019)

Shaded blue area correspond to the estimated 95\% reference range of 7-day moving averages based on 2016-2019. CRCI, COVID-19 related critical illness. Non-CRCI, non-COVID-19 related critical illness. ICU, intensive care unit.

The large number of $\mathrm{CRCl}$ patients with respiratory failure has resulted in a large increase in the number of IMV patients in ICUs. In May 2021, at the peak of the third wave of the pandemic in Ontario, the number of vented patients in Ontario ICUs was $180 \%$ of the pre-pandemic historic average census of vented patients. The vented census has been higher than the historical average since October 25, 2020, corresponding to an ongoing sustained pressure on the province's critical care system. 


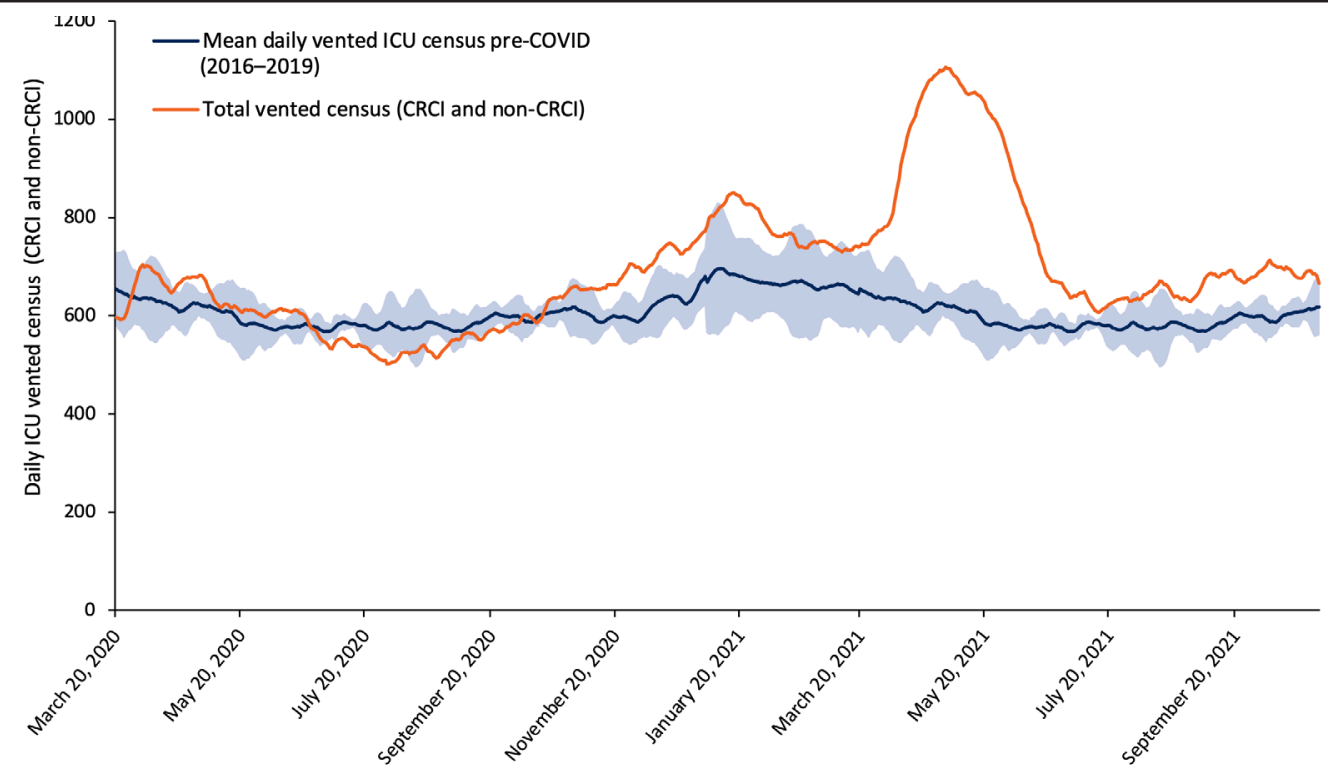

Figure 3. ICU Census for All Adult Ventilated Patients during Pandemic Period Compared to Mean Daily Vented Census for Pre-pandemic Period (2016-2019)

Shaded blue area correspond to the estimated 95\% reference range of 7-day moving averages based on 2016-2019. CRCI, COVID-19 related critical illness. Non-CRCI, non-COVID-19 related critical illness. ICU, intensive care unit.

\section{How Has the Ontario Critical Care System Adapted to Meet the Increased Demand for Critical Care Resources?}

The large number of additional patients requiring critical care during the COVID-19 pandemic required significant and unprecedented situational awareness, collaboration, and coordination between stakeholders and groups, including the Ontario Critical Care COVID-19 Command Centre, Provincial COVID-19 Command Table, Ontario COVID-19 Critical Care Committee, Critical Care Services Ontario, Ontario Health, the Ministry of Health, ORNGE, CritiCall Ontario, hospitals, and long-term care health system partners. ${ }^{5}$ Critical Care Services Ontario, CritiCall Ontario, and ORNGE also provided timely reports to decision makers and stakeholders that were crucial to activity planning, policy development, and enhanced situational awareness.

Policy actions that enabled the critical care system to meet the demands of the increased number of patients included: 1) a reduction in non-emergent surgical and procedural activity to preserve capacity for $\mathrm{CRCl}$ patients; 2) an increase of critical care capacity; and 3) transfers of critically ill patients within and between regions to distribute patients among provincial critical care resources.

\section{Reduction of Non-emergent and Urgent Surgical and Procedural Activity}

The Chief Medical Officer of Health issued directives under the Health Protection and Promotion Act on March 19, 2020, and again on April 20, 2021, requiring that all healthcare providers cease all non-emergent and non-urgent surgical procedures. ${ }^{6}$ These directives were intended to reduce the strain on hospital resources, protect hospital capacity for patients with COVID-19, and free health human resources capacity that could be redeployed to assist with care for patients with COVID-19.

As a result of these directives, there was a dramatic reduction in surgical activity in Ontario hospitals. ${ }^{7}$ The directives were associated with a large decrease in the number of patients who did not have $\mathrm{CRCl}$ (non-CRCl patients) in Ontario ICUs, with a statistically significant greater reduction in the number of non-vented non- $\mathrm{CRCl}$ in ICUs compared to vented non-CRCl patients (Figure 4). Our linear regression model demonstrates that the March 19, 2020 Directive was associated with a decrease in the non-vented census of 524 (95\% confidence interval (Cl) -499 to -550) compared to a decrease of only $69(95 \% \mathrm{Cl}-44$ to -95$)$ in the vented census ( $\mathrm{p}$ for difference 
in reduction between non-vented and vented non-CRCl patients $<0.001)$. The April 20, 2021 Directive was associated with a decrease in the non-vented census of 290 $(95 \% \mathrm{Cl}-253$ to -327$)$, while the decrease in the vented census as a direct result of the Directive was $90(95 \% \mathrm{Cl}-54$ to -128 ; $p$ for difference in reduction between nonvented and vented non- $\mathrm{CRCl}$ patients $<0.001)$.
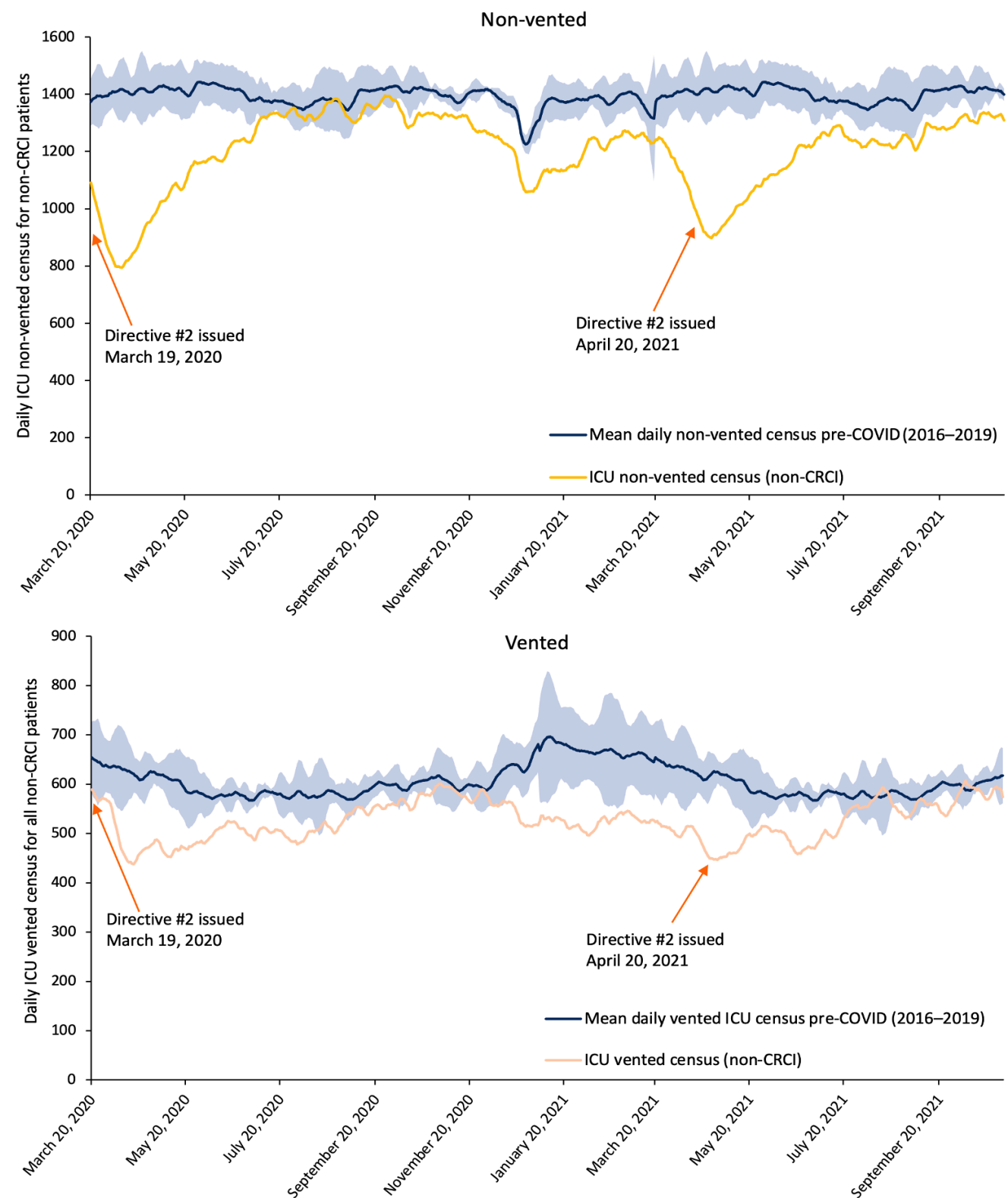

Figure 4. ICU Census Adult Non-CRCI Patients, Vented and Non-vented, Compared to Mean Daily Census for Prepandemic Period (2016-2019)

Shaded blue area correspond to the estimated 95\% reference range of 7-day moving averages based on 2016-2019. CRCI, COVID-19 related critical illness. Non-CRCI, non-COVID-19 related critical illness. ICU, intensive care unit.

While the cessation of non-emergent surgical and procedural activity was certainly responsible for a significant reduction in non-COVID ICU occupancy, other policy changes likely also contributed to it. For example, there was a near complete absence of influenza transmission during the 2020-2021 flu season, likely secondary to the implementation of public health measures intended to reduce transmission of SARSCoV-2, including use of masks, stay at home orders, and adherence to hand hygiene. ${ }^{8}$ The effect of public health measures on non-COVID conditions likely contributed to the reduction in non-COVID-19 volumes in Ontario hospitals and ICUs during the pandemic period. Future research is needed to further describe and quantify the impact of these public health measures on the health system as it relates to non- 
COVID-19 conditions.

\section{Increased Capacity}

Several strategies were employed to expand ICU capacity for $\mathrm{CRCl}$ patients. In fall 2020, there was an investment in 132 new adult ICU beds that were incorporated into baseline ICU capacity. This expansion was in addition to previously committed ICU beds (e.g., the ICU at the newly opened Cortelluci Vaughan Hospital) and included unfunded existing beds in ICUs that could easily be brought into use. In January 2021, to support the Ontario Health Pandemic Plan, ${ }^{9}$ the Government of Ontario announced additional funding for over 500 critical care surge beds. ${ }^{10}$ As a part of this plan, hospitals were asked to create surge plans that identified non-traditional ICU spaces where they could create this additional surge capacity (e.g., operating recovery rooms, step-down/step-up level 2 beds, ward beds). ${ }^{9}$ Critical care leads at Ontario hospitals completed multiple surveys in which they reported their potential additional surge capacity, and at the peak of wave 3 , approximately 600 critical care surge beds had been identified.

This enabled many hospitals to rapidly increase their potential critical care capacity space. The current baseline number of adult critical care beds as at October 31, 2021 is 2,343, reflecting an increase in baseline ICU capacity above the beds added in fall 2020 , but the total number of these new beds that will be permanently funded has not been determined. While ventilator shortage has been described in some jurisdictions, Ontario did not experience a shortage of ventilators during the first 4 waves of the pandemic, even when the number of vented patients in ICU was well above historical averages. Instead, health human resources proved to be the "commodity" that was in short supply.

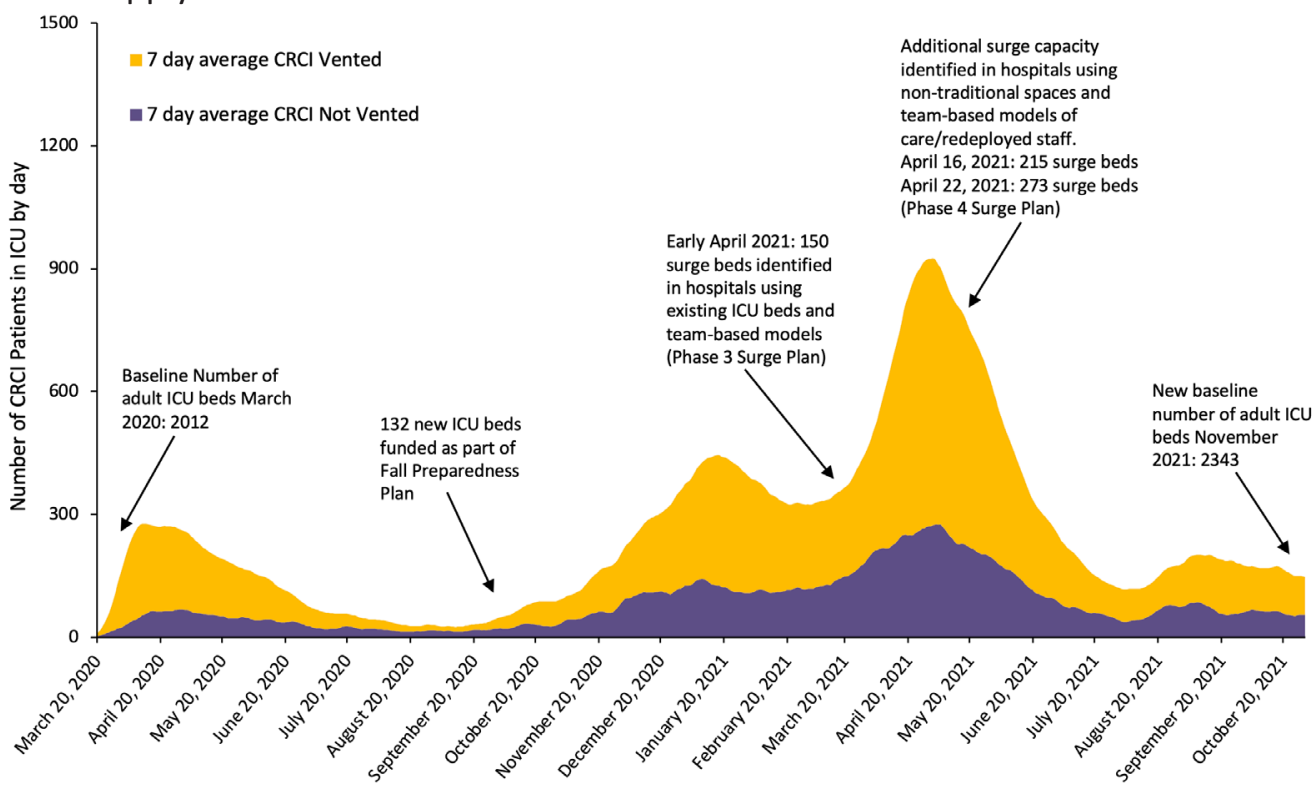

Figure 5. Schematic of How ICU Capacity Was Created through New Beds, Surge Space and Changes to Staffing Models over Time

CRCI, COVID-19 related critical illness. ICU, intensive care unit.

The existing critical care workforce was not sufficient to staff these additional surge beds using traditional staffing models. In some cases, nurses were "doubled" or assigned to two patients, who in a non-surge scenario would each have had one nurse dedicated solely to their care. Another model used was the "team-based model of care". In this model, acute care nurses who normally work in other areas of the hospital (e.g., surgical wards, operating recovery rooms) were redeployed to the ICU and provided bedside care that was within their scope of practice. ICU nurses were assigned to multiple patients and were responsible for providing the care that required 
critical care training, while also supporting the redeployed nurses. This model enabled one critical care nurse to oversee the care of many ICU patients, and dramatically expanded the capacity of the province's critical-care-trained nursing workforce; ${ }^{11}$ however, it was dependant on the redeployment of acute care nurses.
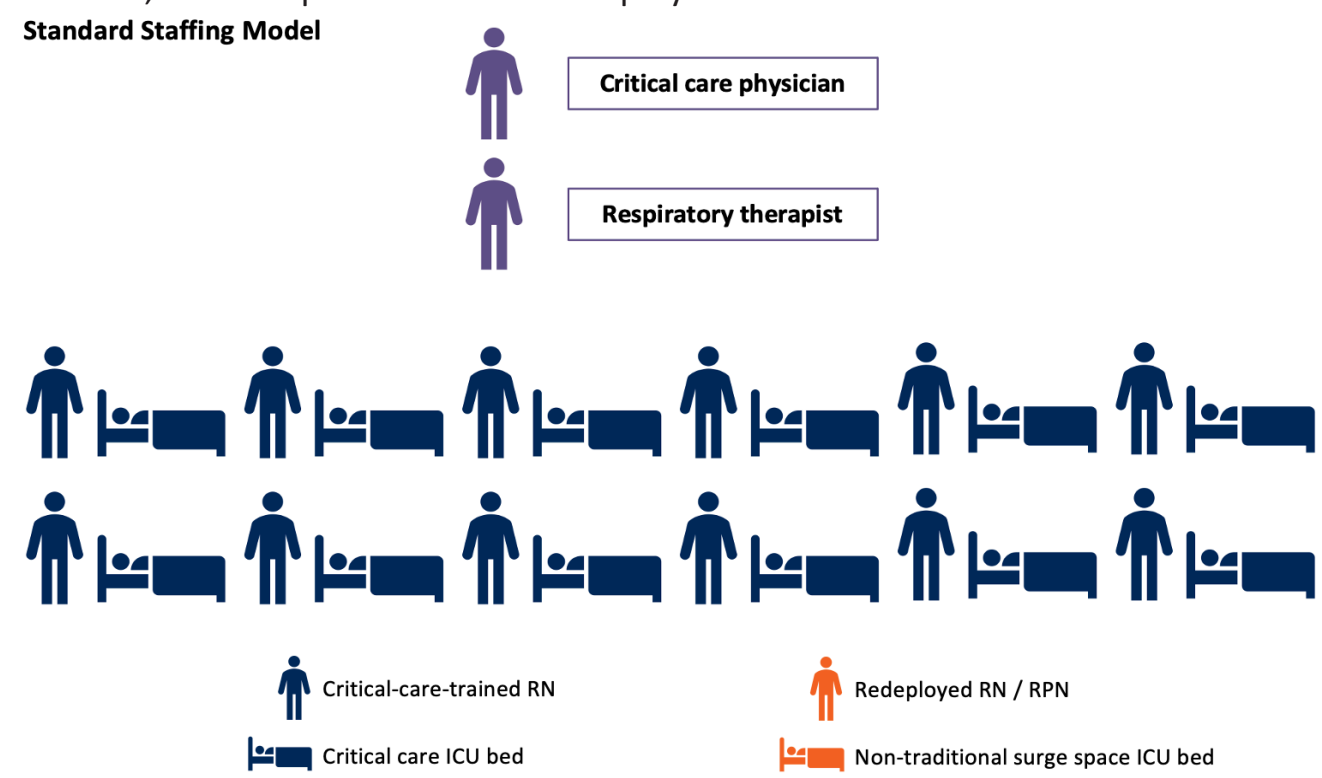

Team-based Model of Care

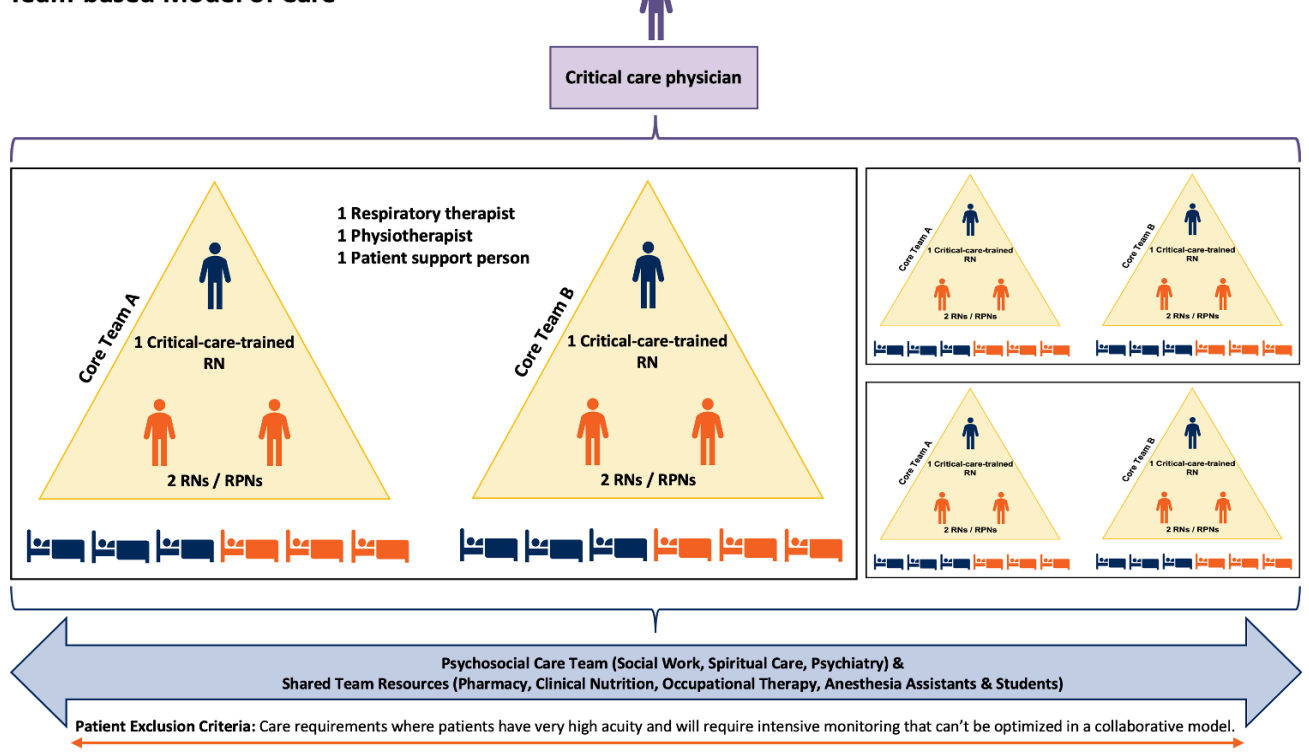

Figure 6. Depiction of ICU Models of Care

Top panel represents the ICU staffing model typically used in level 3 ICUs in Ontario with one critical-care-trained nurse assigned to one critical care patient. Bottom panel depicts team-based model of care used during COVID-19 pandemic period that relied on redeployed non-critical-care-trained nurses and non-traditional surge space. Staffing ratios varied depending on local circumstances and resources and were not always implemented as depicted in this figure. Figure does not include the many learners who were also crucial to the success of this model of care. Adapted from Phase 2 : COVID-19 Pandemic Planning Critical Care Health Human Resources (HHR). Critical Care Command Centre. February $2021 .{ }^{11} I C U$, intensive care unit. $R N$, registered nurse. $R P N$, registered practical nurse.

Many hospitals enacted policies that enabled them to provide IMV to the sickest patients with $\mathrm{CRCl}$. Some converted level 2 non-vented beds into level 3 vented beds. In many hospitals, non-ventilated $\mathrm{CRCl}$ patients on high fractions of inspired oxygen ( $\mathrm{fiO} 2>50 \%$ ) via high-flow nasal cannula were admitted to ward beds. Patients requiring this high level of oxygen would typically be cared for in an ICU, but during the pandemic period many of these patients were cared for in dedicated COVID-19 acute care wards. While it is difficult to quantify the number of patients who received this ICU-level care in wards, it appears that this policy enabled ICUs to preserve their ICU beds for those 
needing IMV. The proportion of patients with $\mathrm{CRCI}$ in ICUs receiving IMV increased from $57 \%$ during mid-March 2021 to over $70 \%$ at the peak of wave 3 . This increase in the proportion of vented patients at the height of wave 3 suggests that hospitals were shifting their non-ventilated patients with $\mathrm{CRCl}$ to hospital wards so that they could accommodate the large numbers of patients with $\mathrm{CRCl}$ who required IMV.

\section{Patient Transfers}

Patients presenting to hospital with $\mathrm{CRCl}$ requiring ICU admission have clustered in regions with the highest burden of SARS-CoV-2 transmission. Toronto, York, and Peel regions were the hardest hit during waves 2 and 3. Between January 5, 2021, and July 4, 2021, the Ontario Critical Care COVID-19 Command Centre directed the transfer of 976 critically ill patients between and within regions. Most of these transfers (832, 85\%) were made proactively to reduce the anticipated burden of COVID-19 in hospitals situated in regions with high rates of community transmission. The remaining $144(15 \%)$ transfers were rescue, offloading hospitals with high censuses and limited capacity to care for additional critically ill patients.

In addition to the transfer of critically ill patients, the Ontario Health-directed Greater Toronto Area Hospital Incident Management System (GTA IMS) Command Centre directed the proactive transfer of 1,696 acute care patients out of hospitals in regions with high rates of community transmission. Many of these patients subsequently required critical care during their admission at receiving hospitals. The transfers of these patients prior to their needing critical care further helped to protect critical care capacity in regions where the concentration of new cases was highest. When adult critical care resources were particularly stretched, adult patients with $\mathrm{CRCl}$ were transferred to pediatric ICU facilities. A total of 42 adults with $\mathrm{CRCl}$ were transferred to Ontario paediatric ICU facilities. All together, they spent a total of 535 days in paediatric ICUs. During waves 3 and 4, Ontario has also accepted $50 \mathrm{CRCl}$ patients from Manitoba and 27 from Saskatchewan.

\section{What Is the Current Status of the Ontario Critical Care System, and What Are the Potential Threats over the Coming Months?}

Ontario is currently in a fourth wave of COVID-19. During October 2021, the average daily census of patients in Ontario critical care beds was $102 \%$ of the pre-pandemic historical average census. The average number of vented patients in Ontario ICUs during October was $114 \%$ of pre-pandemic historical averages. The average nonvented census was just below historical average (97\%). Thus, while the total number of patients in Ontario ICUs during October 2021 was comparable to previous nonpandemic years, the acuity of patients in ICU was higher, with more needing IMV.

There is a growing staffing shortage in Ontario critical care units. ${ }^{12}$ According to the $2017 / 2018$ CCSO biennial workforce survey, the average nursing vacancy rate in Ontario adult critical care units (the percentage of adult critical care nursing positions that were unfilled) was $5.8 \%$. The vacancy rate climbed to $9 \%$ during the period of January-August 2020, months that included the first wave of the COVID-19 pandemic and preceded the addition of newly funded critical care beds to provincial baseline critical care capacity. More recent data on the critical care nursing vacancy rate is not yet available. Anecdotally, it has worsened over the course of the pandemic, and medical leads of some of the ICUs in the province have reported having an insufficient number of nurses to cover all shifts.

Burnout has likely contributed to this staffing shortage. Nurses in particular have been at increased risk for burnout during the pandemic for a variety of reasons, including heighted anxiety about risk of exposure to SARS-CoV-2 at work, an increase in patient acuity, increasing demands for overtime, reassignment to unfamiliar roles, and sustained exposure to the moral distress associated with caring for patients with 
COVID-19. ${ }^{13}$ Burnout among critical care staff was already high at the beginning of the pandemic. In July 2020, CCSO conducted a survey to determine the prevalence of burnout symptoms among the Ontario critical care workforce. Among respondents who worked in an adult level 3 critical care unit, 9.1\% reported feeling complete burnout and $11.7 \%$ reported feeling persistent burnout symptoms. Another $41.4 \%$ reported feeling some burnout symptoms ${ }^{14}$ Over $90 \%$ of survey respondents reported that they felt the COVID-19 pandemic had had a direct impact on their burnout symptoms. ${ }^{14}$ This survey was conducted prior to waves 2 and 3 , and prior to reports of nurses departing the workforce. Burnout among critical care nurses has almost certainly worsened.

In addition to a shortage of critical care nurses and staff, the surge plans that enabled hospitals to accommodate the unprecedented number of additional critically ill patients were contingent on the availability of healthcare workers and space made available through significant reductions in surgical and procedural activity. There is a growing care-deficit among those with non-COVID-19 conditions. This deficit is likely multifactorial, reflecting changes in how people have sought medical care, changes to referral patterns, as well as deferrals of clinical activity. Health system recovery is now a key priority for the Ontario government, and Ontario Health recommendations for hospital operations over the coming months have directed hospitals to preserve access to non-COVID-19 scheduled surgeries, procedures, and diagnostic imaging services. ${ }^{12}$ The healthcare staff and physical space used during the peak of wave 3 will be less readily available in the future as non-COVID-19 care continues.

Recent modelling suggests that there may be an increased number of patients with $\mathrm{CRCl}$ over the next several weeks. Modelling also suggests that there may be a resurgence of influenza-associated hospitalizations and admissions to critical care during the 2021/2022 winter months. ${ }^{15,16}$ The ability of the Ontario critical care system to respond to an increased number of patients needing critical care over the coming months, either due to COVID-19 or influenza-associated respiratory failure, is uncertain.

\section{Interpretation}

The SARS-CoV-2 pandemic has had a considerable impact on the Ontario critical care sector. As a result of unprecedented and effective situational awareness, collaboration, and coordination the worst-case scenario, in which there would be insufficient critical care capacity to care for the number of patients who needed critical care, has thus far been avoided. The pandemic has exacerbated burnout among healthcare workers, and many have left the critical care workforce, thus leading to staffing shortages.

Going forward, it may be more challenging for the critical care system to rapidly increase capacity as it did during the height of wave 3, due to staffing shortages, healthcare worker burnout, and a desire to preserve non-COVID clinical activity.

It is imperative that public health measures that help to reduce transmission of SARS-CoV-2 as well as other infectious diseases with the potential to burden the healthcare system, including influenza, are in place over the coming months. Public health measures will help in the short term; however, longer-term policies need to be simultaneously implemented to address the existing critical care staffing crisis. These combined efforts will help ensure that there is critical care capacity for all patients, COVID-19 and non-COVID-19 who require it, and reduce the burden on an already strained workforce.

\section{Methods Used for This Science Brief}

Unless otherwise stated, all analyses and data are based on daily ICU census data from the Critical Care Information Services (CCIS) database provided to the Ontario 
The CCIS is the most comprehensive source of province-wide information on access to critical care, quality of care, and outcomes for critically ill patients. As part of the Ministry of Health, the CCIS has been developed to provide real-time data on every patient admitted to level 3 and level 2 critical care units in Ontario's acute care hospitals. It is intended to provide the ministry, Ontario Health and sub-regions, and hospitals with information on beds, critical care service utilization, and patient outcomes. ${ }^{17}$ The CCIS is a key component of Ontario's Critical Care Strategy, which is overseen by Critical Care Services Ontario (CCSO). The CCIS provides near-real-time data on every patient admitted to level 3 and level 2 critical care units in Ontario's acute care hospitals. The system also provides information on bed availability, critical care service utilization, and patient outcomes through the 'Reports' functionality. The system is an important medium for monitoring and managing the province's critical care resources more effectively, and for highlighting opportunities to implement quality improvement initiatives at individual hospitals and across regions. ${ }^{3}$

CCSO provided the Ontario COVID-19 Science Advisory Table with CCIS data reporting the total daily census for all adults in ICU (stratified by vented and non-vented as well as CRCI status) for the period from January 1, 2016 to October 31, 2021. CCSO emails health system stakeholders daily reports and a weekly summary of CCIS data as it relates to critical care capacity and COVID-19. Members of the Ontario COVID-19 Science Advisory Table and Secretariat are among those recipients. Those reports were referenced to support this work. The Weekly COVID-19 Summary Report emailed on November 3, 2021, informed the clinical outcomes data for all patients with $\mathrm{CRCI}$.

Information regarding baseline ICU capacity, the funding of new ICU beds, and surge capacity were obtained through personal communication with Cindy VandeVyvere at CCSO, Adil Khalfan at Ontario Health, and Andrew Baker from the Ontario Critical Care COVID-19 Command Centre. Data regarding critical care nurse vacancy trends was provided courtesy of Cindy VandeVyvere at CCSO. Data regarding patient transfers was provided courtesy of Dr. Andrew Baker, from the Ontario Critical Care COVID-19 Command Centre. ${ }^{5}$

To explore the effect of Directive \#2 on ICU census for non- $\mathrm{CRCl}$ vented versus non-vented patients in 2020 and 2021, we developed a linear regression model to determine the change in ICU census after the directives were issued. Variables in the model included vented status, time period (before the directives issued; between directives being issued and when they were rescinded; after the directives rescinded), as well as interaction terms with time to account for changes in directives.

\section{Author Contributions}

$K A B$ conceived of and wrote the first draft of the Science Brief. KAB, GL, and SY performed the analyses. All authors critically reviewed the Science Brief for important intellectual content and approved the final version.

The authors thank Bernard Lawless at CCSO, and Adil Khalfan, Graham Woodward, Rose Cook, Catherine Brown, Emily Hayes, and Ivan Yuen at Ontario Health.

The authors would like to thank Janet MacMillan for copy-editing.

\section{References}

1. Neuraz A, Guérin C, Payet C, et al. Patient mortality is associated with staff resources and workload in the ICU: A multicenter observational study*. Crit Care Med. 2015;43(8):1587-1594. https://doi.org/10.1097/CCM.0000000000001015

2. Canadian Institute for Health Information. Care in Canadian ICUs.; 2016. https:// 
secure.cihi.ca/free_products/ICU_Report_EN.pdf

3. Critical Care Services Ontario. Critical care information system database. CRITICALL Ontario. Published 2021. https://www.criticall.org/Article/CriticalCare-Information-System

4. Intensive Care National Audit \& Research Centre. ICNARC report on COVID-19 in critical care: England, Wales and Northern Ireland, 22 October 2021. ICNARC; 2021. https://www.icnarc.org/our-audit/audits/cmp/reports

5. Critical Care COVID-19 Command Centre. Ontario Health; 2020. https://www. ontariohealth.ca/sites/ontariohealth/files/2020-04/Ontario\%20Health\%20 Critical\%20Care\%20Command\%20Table\%20Backgrounder_23Mar20\%20PDF.pdf

6. Williams DC. COVID-19 Directive \#2 for health care providers (regulated health professionals or persons who operate a group practice of regulated health professionals). Issued under Section 77.7 of the Health Protection and Promotion Act (HPPA), R.S.O. 1990, c. H.7. Ministry of Health; 2020. https://content. oma.org/wp-content/wp-private.php?filename=CMOH_Directive_2-RHPA_ professionals_2020-03-19.pdf

7. Anderson M. Updated - A measured approach to planning for surgeries and procedures during the COVID-19 pandemic. Ontario Health; 2020:37. https:// www.ontariohealth.ca/sites/ontariohealth/files/2020-06/A\%20Measured\%20 Approach\%20to\%20Planning\%20for\%20Surgeries\%20and\%20Procedures\%20 During\%20the\%20COVID-19\%20Pandemic.pdf

8. Nwosu A, Lee L, Schmidt K, Buckrell S, Sevenhuysen C, Bancej C. National influenza annual report, Canada, 2020-2021, in the global context. Can Commun Dis Rep. 2021;47(10):405-413. https://doi.org/10.14745/ccdr.v47i10a02

9. Optimizing care through COVID-19 transmission scenarios. Ontario Health; 2020:39. https://www.ontariohealth.ca/sites/ontariohealth/files/2020-10/ Optimizing\%20Care\%20Through\%20COVID-19\%20Transmission\%20Scenarios_ EN.pdf

10. Government of Ontario. Ontario adding over 500 hospital beds to expand critical care capacity. news.ontario.ca. Published January 18, 2021. https://news.ontario. ca/en/release/59982/ontario-adding-over-500-hospital-beds-to-expand-criticalcare-capacity

11. Phase 2: COVID-19 pandemic planning critical care health human resources (HHR). Critical Care Command Centre; 2021. https://criticalcareontario.ca/wp-content/ uploads/2021/02/HHR_Team-Based-Models-of-Care-Feb-8-2021.pdf

12. Ktytor B. Refreshed recommendations on optimizing care. Ontario Health; 2021. https://www.ontariohealth.ca/sites/ontariohealth/files/2021-10/Refreshed\%20 recommendations\%20on\%20optimizing\%20care.pdf

13. Maunder RG, Heeney ND, Strudwick G, et al. Burnout in hospital-based healthcare workers during COVID-19. Sci Briefs Ont COVID-19 Sci Advis Table. 2021;2(46). https://doi.org/10.47326/ocsat.2021.02.46.1.0

14. Critical Care Services Ontario. Burnout in critical care: Provincial report, 2020 survey. CCSO; 2020. https://criticalcareontario.ca/wp-content/uploads/2020/11/ Provincial-1-Measure-Burnout-Survey-Report.pdf

15. Lee K, Jalal H, Raviotta JM, et al. Predicting the impact of low influenza activity in 2020 on population immunity and future influenza season in the United States. Published online August 30, 2021. https://doi.org/10.1101/2021.08.29.21262803

16. Krauland MG, Galloway DD, Raviotta JM, Zimmerman RK, Roberts MS. Agent- 
based investigation of the impact of low rates of influenza on next season influenza infections. medRxiv. Published online August 26, 2021. https://doi. org/10.1101/2021.08.18.21262185

17. Ministry of Health and Long-Term Care Government of Ontario. Critical Care Information System (CCIS). https://www.health.gov.on.ca/en/pro/programs/ criticalcare/ccis.aspx 